\title{
Bibliothèques monastiques
}

\section{Christophe Didier}

\section{(2) OpenEdition}

Journals

Édition électronique

URL : http://journals.openedition.org/rbnu/806

DOI : 10.4000/rbnu.806

ISSN : 2679-6104

\section{Éditeur}

Bibliothèque nationale et universitaire de Strasbourg

\section{Édition imprimée}

Date de publication : 1 mai 2017

Pagination : 7

ISBN : 9782859230661

ISSN : 2109-2761

\section{Référence électronique}

Christophe Didier, «Bibliothèques monastiques », La Revue de la BNU [En ligne], 15 | 2017, mis en ligne le 01 novembre 2019, consulté le 10 décembre 2020. URL : http://journals.openedition.org/rbnu/806 ; DOI : https://doi.org/10.4000/rbnu.806

\section{(C) $10(0$}

La Revue de la BNU est mise à disposition selon les termes de la Licence Creative Commons Attribution - Pas d'Utilisation Commerciale - Partage dans les Mêmes Conditions 4.0 International. 


\section{DOSSIER \\ BIBLIOTHÈQUES MONASTIQUES}

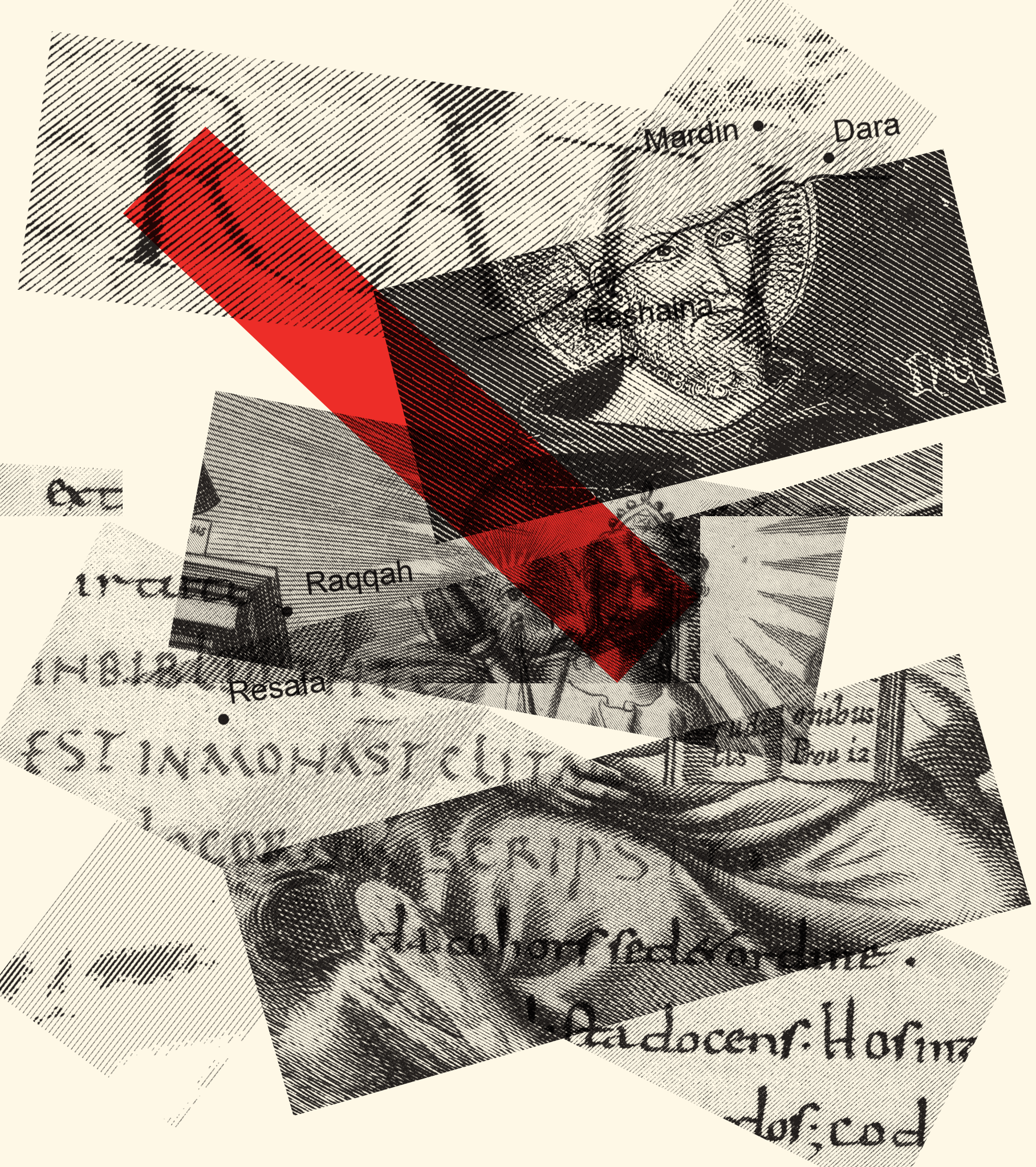


Consacrer un dossier de La Revue de la BNU aux bibliothèques monastiques peut paraître relever de la gageure - non pas tant parce que beaucoup a déjà été écrit sur le sujet, car après tout, la recherche évolue sans trêve -, mais bien plutôt par l'ampleur du sujet même : les bibliothèques monastiques ont été, et sont encore si nombreuses; comment faire tenir ce qui remplirait un ouvrage de référence dans l'espace limité du dossier?

Et puis, n'a-t-on pas là matière à trop de redites ? En France, tout apprenti bibliothécaire connaît par cœur l'histoire des confiscations révolutionnaires, la formation des « dépôts littéraires » qui en est résultée et fut à la base des collections de nos bibliothèques municipales patrimoniales, ces fameuses « bibliothèques municipales classées » qui renferment en leurs murs la plupart des fonds jadis détenus par les monastères, couvents et autres abbayes.

Le sujet vaut-il donc qu'on y revienne ? Nous pensons que oui, car tout d'abord, La Revue n'a jamais souhaité s'arrêter à la France, et a toujours préféré les perspectives transnationales - à l'image des fonds de la Bibliothèque nationale et universitaire de Strasbourg, multilingues et multiculturels dans leur essence, supports d'une recherche appelée à dépasser les frontières. Et si l'on connaît chez nous le sort des bibliothèques d'abbayes et de couvents à la Révolution, sait-on qu'il en fut de même au début du $19^{\mathrm{e}}$ siècle en Allemagne par exemple, avec la fameuse " sécularisation " qui dispersa sur presque tout le territoire les possessions ecclésiastiques, avant qu'un mouvement inverse, dans certaines régions du pays, ne fasse un peu plus tard revenir moines et moniales, avec leurs biens plus ou moins amputés, sur leurs lieux d'origine ? Par ailleurs, les bibliothèques monastiques existent toujours (les moines et les moniales aussi !) et il n'est pas sans intérêt de rappeler là qu'il ne s'agit pas seulement d'un enjeu patrimonial, mais bien de la pratique contemporaine d'une pensée - et des outils dont elle se sert, qui la fondent et lui donnent parfois aussi sa justification. Quant aux fonds plus anciens, moins utilisés certes mais au prestige et à la force symbolique intacts, il serait faux de penser qu'ils ont systématiquement fini leur course sur un rayonnage obscur, à l'abri des outrages du temps, mais privés pour jamais de toute valeur d'usage.

Les bibliothèques monastiques ont un passé glorieux, une histoire récente turbulente, et cela sans doute justifierait déjà que la revue d'une grande bibliothèque patrimoniale s'y intéresse ; elles ont aussi une actualité (parfois rassurante, parfois tragique, comme nous le rappellent périodiquement les nouvelles en provenance de l'Afrique, du Proche- et du Moyen-Orient) et des perspectives d'avenir plus variées qu'on ne pourrait le croire au premier abord. Tous ces aspects, le présent numéro les abordera sous un double angle de vue : chronologique d'abord, en rappelant quelles furent les origines du modèle occidental et partant, quelles fonctions l'on assignait aux bibliothèques au sein de ces communautés religieuses et intellectuelles qui ont forgé une part non négligeable du patrimoine culturel qui est le nôtre aujourd'hui - sans oublier l'histoire plus récente, des Temps modernes au monde contemporain, et la façon dont les bibliothèques monastiques ont eu à subir les évolutions politiques, sociétales, spirituelles et culturelles de quinze siècles d'histoire européenne et mondiale. En même temps, nous avons souhaité que chaque exemple envisagé ici puisse être vu comme une étude de cas, une image emblématique de ce que peut signifier, aujourd'hui, la notion même de bibliothèque monastique : bibliothèques au sens plein du terme, utilisées par les religieux seuls ou ouvertes aux chercheurs extérieurs, fonds nomades ayant été incorporés, avec plus ou moins de pertes, à des ensembles plus importants, fonds dispersés reconstitués virtuellement, existence, histoire et devenir aussi de modèles monastiques parfois proches, parfois plus éloignés de nos traditions européennes et occidentales.

Les monastères, couvents et autres abbayes ont dans nos sociétés des loisirs un fort pouvoir d'attraction touristique, où entre une certaine part de nostalgie de temps anciens considérés, à tort ou à raison, comme plus tranquilles et à l'abri des tumultes du monde. Cloîtres, salles capitulaires, réfectoires ou cellules font partie intégrante de cet imaginaire collectif. Faire redécouvrir leurs bibliothèques, c'est aussi montrer qu'ils furent - et sont toujours des lieux d'étude, que ceux-ci se déploient derrière les murs de pierres séculaires ou sur les écrans de nos outils contemporains.

\section{Christophe Didier}

